\title{
Removal of Polysialic Acid Triggers Dispersion of Subventricularly Derived Neuroblasts into Surrounding CNS Tissues
}

\author{
Daniela Battista and Urs Rutishauser \\ Laboratory of Cellular and Developmental Neuroscience, Department of Cell Biology, Memorial Sloan-Kettering Cancer Center, New York, New York 10021
}

Cells generated in the subventricular zone give rise to neuroblasts that migrate to the olfactory bulb (OB) along the rostral migratory stream (RMS). The polysialylated form of neural cell adhesion molecule (PSA-NCAM) is expressed by these cells, and has been shown to both promote their migration and suppress differentiation induced by NCAM. In the present study, enzymatic removal of PSA from these neuroblasts using PSA-specific endoneuraminidase has been found not only to disrupt the tangential migration and cellular organization of the RMS, but also to cause a massive dispersion of $\mathrm{BrdU}$ (5-bromo-2'-deoxyuridine)-labeled neuroblasts into surrounding brain regions, including cortex and striatum. These dispersed cells are capable of differentiation, some into mature neurons, and could potentially be of value in the repair of CNS injury. Although the removal of PSA by genetic deletion of NCAM also results in a smaller OB and a swollen RMS, the cells do not escape the RMS in large numbers. These findings suggest that the presence of NCAM without PSA plays a role in the dispersion process, possibly by inducing a new pattern of migration associated with NCAM-dependent differentiation.

\section{Introduction}

New olfactory bulb (OB) neurons of adult mammals are generated from multipotent stem cells that reside mostly in the subventricular zone (SVZ) lining the lateral ventricle (Altman, 1969; Luskin et al., 1993). SVZ cells give rise to dividing neuroblasts that migrate to the OB following a well defined pathway, the rostral migratory stream (RMS) (Lois and Alvarez-Buylla, 1994). On reaching the $\mathrm{OB}$, neuroblasts migrate radially and differentiate into interneurons of the granular and periglomerular layers (Kosaka et al., 1995; Peretto et al., 1999; Carleton et al., 2003). RMS neuroblasts are arranged in a network of arrays or "chains" surrounded by astrocytes that envelope them, forming a tube-like structure (Peretto et al., 1997). It has been proposed that this organization of neuroblasts allows them to use each other as a migratory substrate (Hu et al., 1996).

The highly polysialylated form of the neural cell adhesion molecule (PSA-NCAM) is expressed by neuroblasts along the RMS (Bonfanti and Theodosis, 1994; Rousselot et al., 1995). The presence of PSA at the cell surface is known to reduce cell-cell interactions (Rutishauser, 1998). A role for PSA-NCAM in rostral migration has been demonstrated using NCAM-deficient mice, which have a smaller olfactory bulb and an accumulation of cells in the SVZ and RMS (Tomasiewicz et al., 1993; Cremer et al., 1994). Similar defects are observed when PSA but not NCAM is destroyed in vivo using the PSA-specific endoneuraminidase $\mathrm{N}$ (endoN) (Ono et al., 1994).

\footnotetext{
Received Sept. 2, 2009; revised Jan. 11, 2010; accepted Jan. 15, 2010.

We thank Dr. El Maarouf for critical reading of this manuscript and suggestions during the course of this work.

Correspondence should be addressed to Dr. Urs Rutishauser, Memorial Sloan-Kettering Cancer Center, 1275 York

Avenue, New York, NY 10021. E-mail: u-rutishauser@mskcc.org.

DOI:10.1523/JNEUROSCI.4382-09.2010

Copyright $\odot 2010$ the authors $\quad 0270-6474 / 10 / 303995-09 \$ 15.00 / 0$
}

PSA appears to influence neuroblast differentiation as well as rostral migration. This carbohydrate is downregulated once cells reach the $\mathrm{OB}$ and begin to migrate radially and differentiate. Furthermore, removal of PSA has been correlated with the appearance of ectopically differentiated cells within the RMS (Chazal et al., 2000; Petridis et al., 2004), and PSA can influence cell differentiation in vitro (Decker et al., 2000; Seidenfaden et al., 2003; Röckle et al., 2008). Mice deficient for the enzyme that synthesizes PSA (STSiaII/STSiaIV) (Eckhardt et al., 2000; Weinhold et al., 2005) also show migration defects, but with a more severe phenotype than the NCAM mutants, suggesting that PSA-free NCAM itself can play a role in these events.

In the present study, we initially intended to focus on the differentiation fates of 5-bromo- $2^{\prime}$-deoxyuridine (BrdU)-labeled neuroblasts in endoN-treated adults. To our surprise, we found a previously undocumented consequence of PSA removal: migration of large numbers of BrdU-labeled cells out of the RMS and deep into surrounding brain regions. Migration of small numbers of cells into non-olfactory bulb regions has been observed in early postnatal rodent brain (Suzuki and Goldman, 2003; De Marchis et al., 2004; Inta et al., 2008) and adult rabbit brain (Luzzati et al., 2003), and in response to injury (Magavi and Macklis, 2001; Arvidsson et al., 2002; Iwai et al., 2003; Goings et al., 2004; El Maarouf et al., 2006; Zhang et al., 2007). An increase in the number of neural precursors that can deviate from their canonical route in response to PSA removal could provide a valuable tool in the treatment of brain injury or neurodegenerative diseases.

\section{Materials and Methods}

Animals. Two-month-old BALB/c mice (Charles River Laboratories) or NCAM-null mutant mice (C57BL) (Cremer et al., 1994) were used throughout the study. Mice were kept under controlled temperature, and food and water were available ad libitum. All experimental procedures 


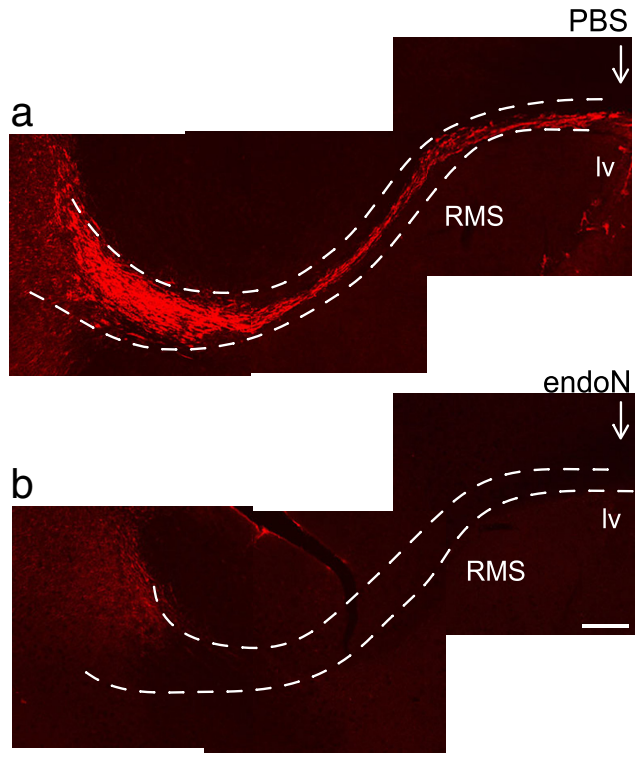

Figure 1. Removal of PSA from the RMS by endoN. $\boldsymbol{a}, \boldsymbol{b}$, PSA-NCAM immunofluorescence of sagittal sections of the RMS (dotted line). Either PBS (a) or endoN $(\boldsymbol{b})$ was injected into the ventricle of 8-week-old BALB/c mice, and the tissue was examined after $10 \mathrm{~d}$. Arrows indicate the injection site. Iv, Lateral ventricle; RMS, rostral migratory stream. Scale bar, $200 \mu \mathrm{m}$.
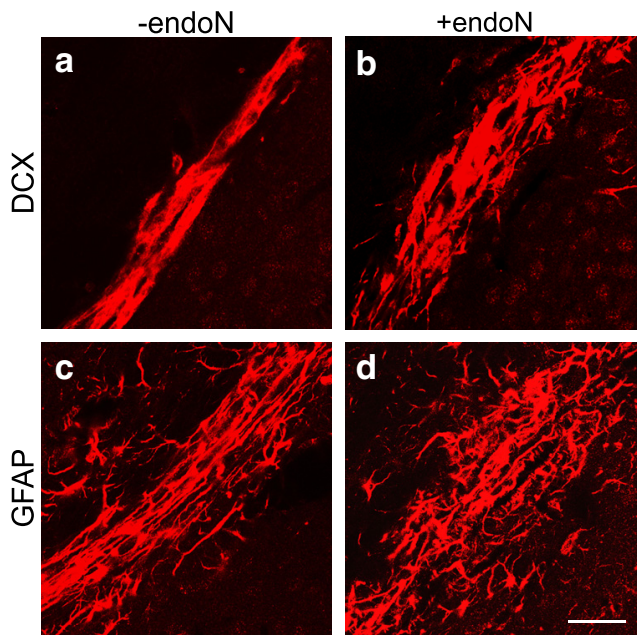

Figure 2. Altered organization of the RMS in endoN-treated mice. $\boldsymbol{a}-\boldsymbol{d}$, Immunofluorescence for DCX $(\boldsymbol{a}, \boldsymbol{b})$ and GFAP $(\boldsymbol{c}, \boldsymbol{d})$ of sagittal sections of the RMS. The removal of PSA caused the disorganization of the RMS and neuroblast alignment with a loosening of the normally compact, tube-like astrocytic architecture. Glial processes were more scattered and not arranged tangential to the direction of neuroblast migration. A disruption of the tube-like structure can be seen. Note that the RMS has a wider diameter in endoN-treated brains. Scale bar, $20 \mu \mathrm{m}$.

were performed according to National Institutes of Health and institutional animal use guidelines.

EndoN treatment and BrdU labeling. Animals were anesthetized with sodium pentobarbital $(10 \mathrm{mg} / \mathrm{kg})$ and injected with either $1 \mu \mathrm{l}$ of PBS or $1 \mu \mathrm{l}$ of endoN ( 10 units/ $\mu \mathrm{l}$ ) in the lateral ventricle over a $10 \mathrm{~min}$ period. endoN is a phage enzyme that specifically cleaves $\alpha 2,8$-linked sialic acid polymers and diffuses rapidly in tissues, selectively removing PSA (Vimr et al., 1984; Hallenbeck et al., 1987; El Maarouf and Rutishauser, 2003). A single injection of endoN in the adult brain removes PSA broadly within $2 \mathrm{~d}$ and remains effective for at least 3 weeks (Ono et al., 1994). The injections were performed with a $50 \mu \mathrm{m}$ tipped, fine-glass capillary at coordinates, from bregma: posterior, $0.8 \mathrm{~mm}$; lateral, $0.8 \mathrm{~mm}$; ventral to the surface of the brain, $1.8 \mathrm{~mm}$. Both hemispheres were injected. Ten a

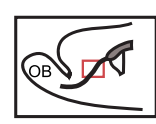

RMSp

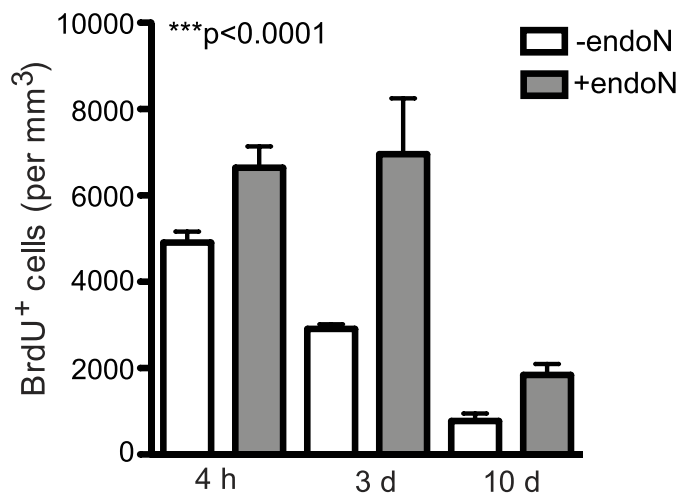

b
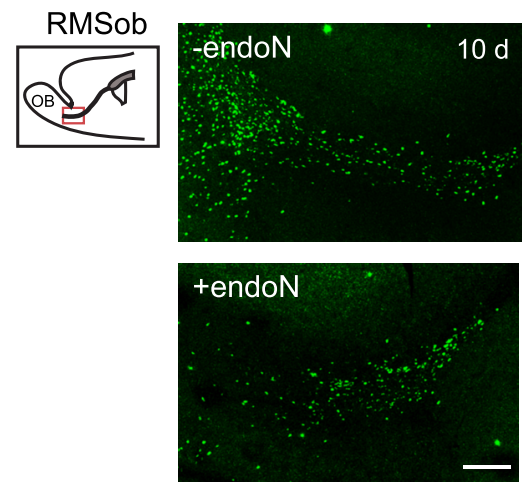

Figure 3. Quantification of BrdU ${ }^{+}$cells along the RMS at different time points. $\boldsymbol{a}$, Number of $\mathrm{BrdU}^{+}$cells along the RMS of PBS-injected (-endoN) or endoN-injected (+ endoN) mice. Animals received a single BrdU injection $10 \mathrm{~d}$ after the intracranial injections and were killed at different time points ( $4 \mathrm{~h}, 3 \mathrm{~d}$, and $10 \mathrm{~d}$ after the BrdU injection). Cells were quantified in the RMSp (inset). $\boldsymbol{b}$, Representative photomicrographs of BrdU immunofluorescence in the RMSob. Note that the increase in the number of $\mathrm{BrdU}^{+}$cells in the RMSp after PSA was removed was accompanied by a decrease in the number of cells that reached the $O B$, suggesting that cells are failing to migrate tangentially toward the olfactory bulb. It cannot be determined whether the increase in the number of cells in endoN-treated mice at $4 \mathrm{~h}$ compared with controls is due to cell retention or increased cell proliferation, and may in fact reflect a mixture of both phenomena. Values are the mean $\pm \mathrm{SEM} ;{ }^{* * *} p<$ 0.0001, ANOVA ( $4 \mathrm{~h}:-$ endoN, $n=3$ mice; + endoN, $n=3$ mice; 3 and $10 \mathrm{~d}:-$ endoN, $n=5 ;+$ endoN, $n=6$ mice). Scale bar, $200 \mu \mathrm{m}$.

days after the intraventricular injection, animals were injected intraperitoneally with BrdU (Sigma-Aldrich; $50 \mathrm{mg} / \mathrm{kg}$ body weight dissolved in $0.1 \mathrm{~N} \mathrm{NaOH}, 0.9 \% \mathrm{NaCl})$ and killed at different time points $(4 \mathrm{~h}, 3 \mathrm{~d}$, and $10 \mathrm{~d}$ from the BrdU injection). For analysis of cell differentiation at longer time points, animals received a total of six injections (twice daily, $4 \mathrm{~h}$ apart, over 3 consecutive days) and killed $21 \mathrm{~d}$ after the end of treatment. At specific time points, animals were deeply anesthetized and perfused through the heart with PBS and 4\% paraformaldehyde in 0.1 $\mathrm{mol} / \mathrm{L}$ phosphate buffer $(\mathrm{PB}), \mathrm{pH}$ 7.4. Brains were removed and postfixed overnight at $4^{\circ} \mathrm{C}$ in $4 \%$ paraformaldehyde. Brains were sliced in a vibrating microtome (Pelco-101, Ted Pella) in 40- $\mu$ m-thick sagittal sections.

Immunohistochemistry. For BrdU immunofluorescence, free-floating sagittal sections were pretreated with $2 \mathrm{~N} \mathrm{HCl}$ for $30 \mathrm{~min}$ at $37^{\circ} \mathrm{C}$ to denature DNA, rinsed in $0.1 \mathrm{~m}$ borate buffer, $\mathrm{pH} 8.5$, and thoroughly washed in Tris-buffered saline (TBS; $50 \mathrm{~mm}$ Tris-HCl, pH 7.4, $150 \mathrm{~mm}$ $\mathrm{NaCl}$ ). Sections were then blocked in $0.1 \%$ Triton X-100, 5\% donkey serum in TBS for $30 \mathrm{~min}$ at room temperature (RT) and incubated $48 \mathrm{~h}$ at $4^{\circ} \mathrm{C}$ with different antibodies: rat anti-BrdU (1:300, AbD, Serotec), mouse anti-calbindin (1:200, Abcam), goat anti-calretinin (1:300, Santa 
a

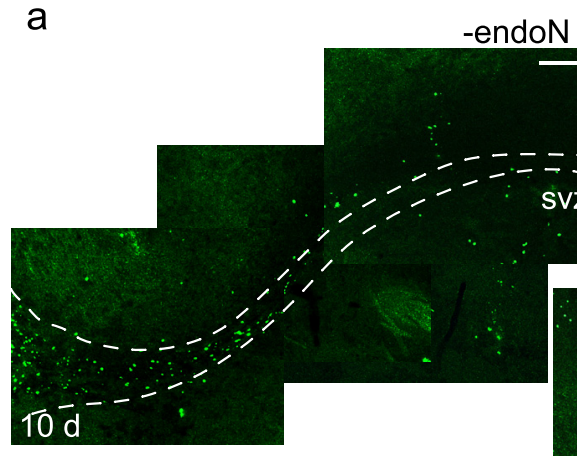

b
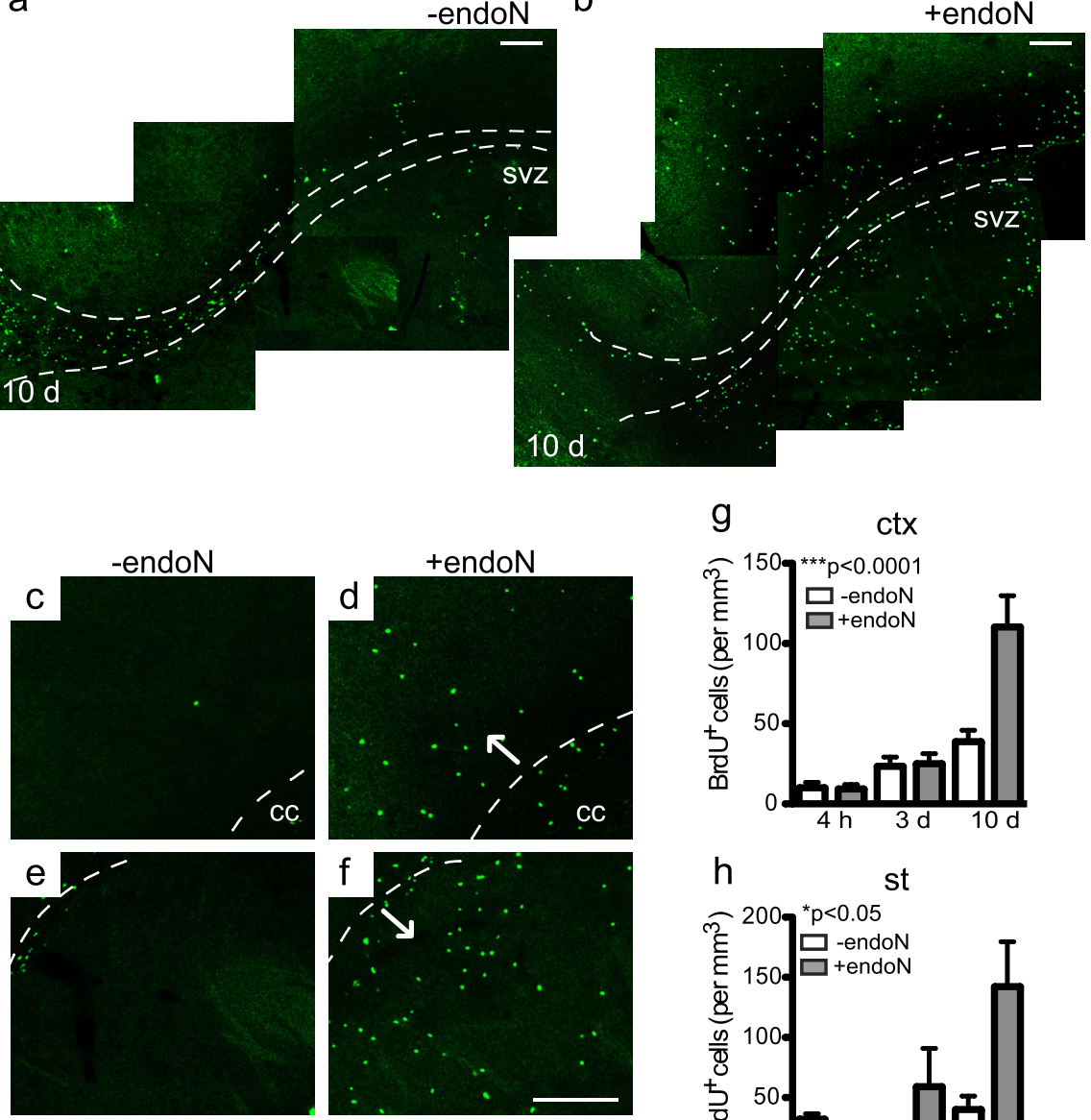

$\mathrm{g}$



$\mathrm{h}$

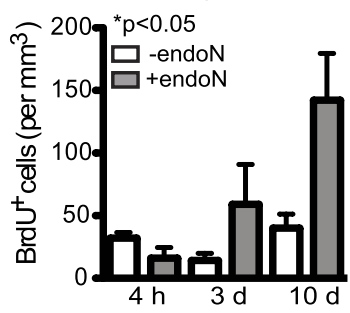

Figure 4. Analysis of the BrdU ${ }^{+}$cell population outside the RMS. $\boldsymbol{a}, \boldsymbol{b}, \mathrm{BrdU}$ immunofluorescence of control $(\boldsymbol{a})$ and endoNtreated $(\boldsymbol{b})$ mice $10 \mathrm{~d}$ after the BrdU injection. Representative photomicrographs of sagittal sections are shown. The dotted line outlines the RMS. Note the reduced number of cells in more anterior portions of the RMS (b) (Fig. 3b) and the increased number of cells outside the RMS. $\mathbf{c} \boldsymbol{f}$, High-magnification image of BrdU staining in the cortex and striatum. Many positive cells can be seen in both areas after PSA has been removed $(\boldsymbol{b}, \boldsymbol{d}, \boldsymbol{f})$. The dotted line outlines the corpus callosum in $\boldsymbol{c}$ and $\boldsymbol{d}$, and the RMS in $\boldsymbol{e}$ and $\boldsymbol{f}$. $\boldsymbol{g}, \boldsymbol{h}$, Quantification of $\mathrm{BrdU}^{+}$cells in the cortex $(\boldsymbol{g})$ and the striatum $(\boldsymbol{h})$ at different time points. An increase in the density of $\mathrm{BrdU}^{+}$cells was seen over time when PSA was removed. Values are the mean \pm SEM; ${ }^{*} p<0.05,{ }^{* * *} p<0.0001$, ANOVA ( $4 \mathrm{~h}$ : - endoN, $n=3$ mice; + endoN, $n=3$ mice; 3 and $10 \mathrm{~d}:-$ endoN, $n=5$ mice; + endoN, $n=5$ mice). cc, Corpus callosum; ctx, cortex; st, striatum. Scale bar, $100 \mu \mathrm{m}$.

Cruz Biotechnology), guinea pig anti-doublecortin (DCX) (1:400, Millipore Bioscience Research Reagents), mouse anti-GABA (1:400, Sigma), rabbit anti-GFAP (1:700, Abcam), mouse anti-nestin (1:200, DSHB), mouse anti-NeuN (1:400, Millipore Bioscience Research Reagents), and mouse anti-Tuj1 (1:100, Abcam). For PSA immunofluorescence, freefloating sections were rinsed in PBS, blocked in 5\% goat serum in PBS for 30 min at RT, and incubated overnight at $4^{\circ} \mathrm{C}$ with mouse IgM anti-PSA (1:1000, 5A5). Sections were then washed twice with PB and incubated with secondary antibodies: Cy2-, Cy3-, and Cy5-conjugated donkey antibodies (1:400, Jackson ImmunoResearch). For PSA, a Cy3-conjugated goat anti-IgM was used (1:500, Jackson ImmunoResearch). For DCX, a biotin-conjugated donkey anti-guinea pig antibody was used followed by incubation with Cy3 or Cy5 streptoavidin (1:400, Jackson ImmunoResearch). All incubations were performed for $2 \mathrm{~h}$ at RT, and sections were washed twice in PB. Some sections were incubated for $10 \mathrm{~min}$ with TOTO-3 iodide (1:1000, Invitrogen) before treatment with $1 \mu \mathrm{g} / \mathrm{ml}$ RNaseI (Promega). Sections were mounted in Mowiol (Calbiochem).

Terminal deoxynucleotidyl transferase-mediated biotinylated UTP nick end labeling staining and annexin $V$ labeling. Apoptosis was detected by the terminal deoxynucleotidyl transferase-mediated biotinylated UTP nick end labeling (TUNEL) method, according to manufacturer's in- structions (GenScript). Labeled samples were treated with diaminobenzidine (DAB) to visualize positive apoptotic cells. Both positive and negative controls were included in the test. Sections were counterstained with Nissl stain, and the number of positive cells was analyzed under a light field microscope. For annexin V labeling, free-floating sections were rinsed once in PBS, blocked in 5\% goat serum without Triton $\mathrm{X}-100$ for $30 \mathrm{~min}$, and incubated overnight at $4^{\circ} \mathrm{C}$ with anti-annexin $\mathrm{V}$ antibody conjugated to Alexa Fluor-488 (1:50, Invitrogen).

Quantification and imaging. One in three sagittal sections along the mediolateral axis of the brain was analyzed for each immunolabeling. Digital images were collected by a Zeiss LSM 510 laser-scanning confocal microscope with three lasers (Argon 488, HeNe 543, and $\mathrm{HeNe} 633$ ) with a c-Apochromat $40 \times$ objective (water immersion). For BrdU quantification alone, positive cells were counted in defined regions of the brain; RMS, corpus callosum, cortex, striatum, and OB. Only brain sections encompassing the SVZ-RMS axis were considered, and the entire region was taken into account. Sections more lateral or more medial to the RMS were not taken into consideration. The RMS was divided in two regions: the caudal portion of the RMS (RMSp) proximal to the SVZ; and the rostral portion of the RMS (RMSob) right before entering the OB. The total number of cells counted on both hemispheres was averaged and normalized to the volume analyzed (number of $\mathrm{BrdU}^{+}$cells per cubic millimeter). For BrdU doublestaining analysis at 10 and $21 \mathrm{~d}$, confocal $z$-scanning was performed at $0.8 \mu \mathrm{m}$ intervals through the entire $z$-axis $(20-40 \mu \mathrm{m})$ with a pinhole of $1 \mu \mathrm{m}$. Double-labeled cells were analyzed in single optical planes through the entire $z$-axis. Eighty to $150 \mathrm{BrdU}^{+}$cells were analyzed (total number of animals: $10 \mathrm{~d}, n=6$; $21 \mathrm{~d}, n=5$ ), and the percentage of doublelabeled cells from the total $\mathrm{BrdU}^{+}$cell population was quantified. For BrdU/DCX ${ }^{+}$cell quantification, the number of positive cells in the corpus callosum and striatum was estimated from the quantification of the percentage of double-labeled cells and the total number of $\mathrm{BrdU}^{+}$cells present in each region. Approximately 50 cells were analyzed for each treatment (total number of animals; - endoN, $n=3$; + endoN, $n=3$ ).

Statistical analysis. Data are presented as the mean \pm SEM. Comparisons were performed using Student's $t$ test and one-way ANOVA followed by post hoc Bonferroni test. Differences were considered significant at ${ }^{*} p<0.05,{ }^{* *} p<0.01$, and ${ }^{* *} p<0.0001$.

\section{Results}

EndoN injection into the lateral ventricle removes PSA and alters the structure of the RMS

To analyze the effect of PSA removal on neuroblast migration and differentiation, the lateral ventricle of adult BALB/c mice was injected with endoN. PSA immunofluorescence studies confirmed that the injection of endoN removed PSA from the brain (Fig. 1). Immunostaining of brain sections with DCX, a protein expressed by migrating neuroblasts, showed that removal of PSA loosened the compact and aligned organization of neuroblasts in the RMS (Fig. 2a,b). The pathway had a wider diameter, and 
individual cells altered their morphology from an orderly, tangential orientation to a tangle of cell bodies and less organized processes.

In the intact RMS, astrocytes ensheath the migrating neuroblasts, seemingly separating them from the surrounding tissue (Peretto et al., 1997). GFAP immunostaining of endoN-treated animals showed a disruption of this tube-like structure, with an increase in the number of astrocytic processes not aligned in the direction of neuroblast migration (Fig. $2 c, d$ ). These disorganized processes were often thicker and shorter than in control animals.

\section{Migration of neuroblasts is altered in the RMS of endoN-treated brains}

In previous studies, the effect of PSA or PSA-NCAM removal on the RMS was assessed by observing the total number of cells in this structure, for example by Nissl staining. Here, to visualize dividing neuroblasts, PBS or endoN-treated brains were injected with BrdU. The animals were killed at different time points $(4 \mathrm{~h}$, $3 \mathrm{~d}$, and $10 \mathrm{~d}$ after the BrdU injection), and the density of BrdU ${ }^{+}$ cells determined in the caudal region of the RMS. The density of BrdU-labeled cells in the normal RMS decreased with time (Fig. $3 a$ ), as would be expected from their known rostral migration toward the olfactory bulb (Lois and Alvarez-Buylla, 1994). These data also agree with previous reports using BrdU labeling (Alonso et al., 1999; Decker et al., 2002). Similarly, the observed increase in the numbers of $\mathrm{BrdU}^{+}$cells in the RMS of endoN-treated brains relative to controls at each time point (Fig. $3 a$ ) is consistent with an inhibition of migration (Ono et al., 1994; Petridis et al., 2004). The marked decrease in the values obtained for the endoN-treated animals by day 10 suggested that the effects of PSA removal delayed rather than blocked migration. It was therefore anticipated that the analysis of PSA-negative caudal RMS (RMSob) (Fig. $3 b$ ) at $10 \mathrm{~d}$ would reveal a density of BrdU-labeled cells equal to or greater than that observed in controls. Instead, what was found was a clear decrease in the number of BrdU ${ }^{+}$cells in this region, as well as in the number of labeled cells that had reached the $\mathrm{OB}\left(-\right.$ endoN $=5025 \pm 325 \mathrm{BrdU}^{+}$cells $/ \mathrm{mm}^{3}$ vs + endoN $=3033 \pm 867 \mathrm{BrdU}^{+}$cells $/ \mathrm{mm}^{3} ; p<0.05$, Student's $t$ test) (Fig. $3 b)$.

\section{Large numbers of BrdU-labeled cells are present outside the RMS in endoN-treated brains}

When brain sections were analyzed for BrdU staining outside the RMS $10 \mathrm{~d}$ after the BrdU injection, a large increase in the density of positive nuclei was seen after PSA had been removed (Fig. $4 a, b)$. Detailed analysis revealed many positive cells in the cortex and striatum that were not seen in control animals (Fig. $4 c-f$ ). The quantification of $\mathrm{BrdU}^{+}$cells at different time points showed an increase in the number of cells over time (Fig. $4 g, h$ ). Analysis of cell proliferation outside the RMS ( $4 \mathrm{~h}$ ) did not reveal any difference in the number of $\mathrm{BrdU}^{+}$cells between control and endoN-treated brains, indicating that the presence of ectopic $\mathrm{BrdU}^{+}$cells in these areas at $10 \mathrm{~d}$ was not attributable to increased cell proliferation (Fig. $4 g, h$ ). Differences in apoptosis between PBS- and endoN-injected brains were not observed in sections analyzed for TUNEL staining and annexin $\mathrm{V}$ labeling (Fig. 5)

To further characterize this phenomenon, the cellular structure of the RMS and its immediate surroundings were examined in closer detail at $3 \mathrm{~d}$, at which time many $\mathrm{BrdU}^{+}$cells still appeared to be retained in the PSA-negative RMS. As described previously, a disorganization of the RMS occurred with endoN treatment (Fig. $6 a-e$ ). Neuroblasts could be seen streaming out
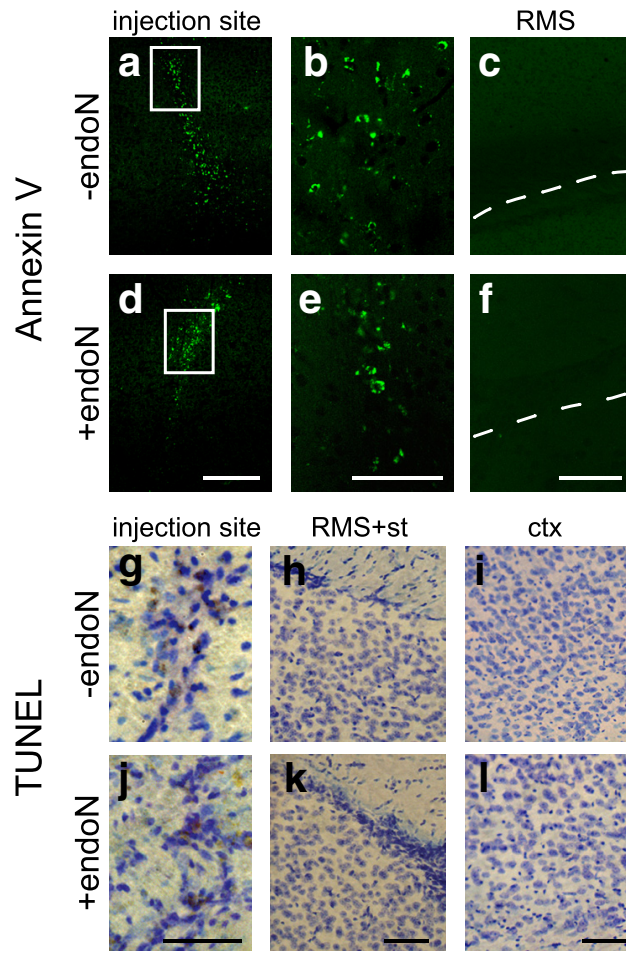

RMS+st

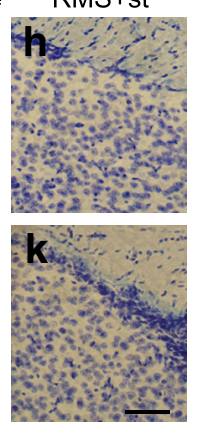

$\operatorname{ctx}$

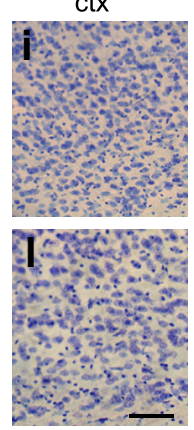

Figure 5. Analysis of apoptosis. $\boldsymbol{a}-\boldsymbol{f}$, Representative photomicrographs showing annexin $V$ staining of sagittal sections of control $(\boldsymbol{a}-\boldsymbol{c})$ and endoN-treated $(\boldsymbol{d}-\boldsymbol{f})$ brains $10 \mathrm{~d}$ after PBS or endoN injection. Positive cells can be seen around the injection site for both treatments $(\boldsymbol{a}, \boldsymbol{b}, \boldsymbol{d}$, $\boldsymbol{e})$. Very few positive cells were seen in the RMS and surrounding tissue, and no differences were seen between treatments. $\boldsymbol{g}-\boldsymbol{I}$, Representative micrographs showing TUNEL staining (DAB) of sagittal sections of control $(\boldsymbol{g}-\boldsymbol{i})$ and endoN-treated $(\boldsymbol{j}-\boldsymbol{I})$ brains $10 \mathrm{~d}$ after PBS or endoN injection. Some positive cells can be seen around the injection site $(\boldsymbol{g}, \boldsymbol{j})$ for both treatments, but very few positive cells could be seen in the RMS $(\boldsymbol{h}, \boldsymbol{k})$ or the cortex $(\boldsymbol{i}, \boldsymbol{I})$. No differences in the number of apoptotic cells were seen between treatments. Sections were counterstained with Nissl stain. ctx, Cortex; st, striatum. Scale bars: a, c, $200 \mu \mathrm{m} ; \boldsymbol{b}, 100 \mu \mathrm{m} ; \boldsymbol{g}-\mathbf{l}, 50 \mu \mathrm{m}$.

of the RMS, well into the surrounding tissue (Fig. $6 d, e$ ), including the striatum (Fig. 6f,g) and the corpus callosum (Fig. 6h-k). Moreover, many of these neuroblasts appeared to be aligned orthogonal to their natural direction of migration (Fig. $6 a, b$ ). When the density of double-labeled BrdU/DCX ${ }^{+}$cells per cubic millimeter at $3 \mathrm{~d}$ was analyzed by $z$-scanning confocal microscopy, an increase in the number of cells was observed for both the striatum $(-$ endoN $=1.6 \pm 0.65$ cells vs + endoN $=36 \pm 15.3$ cells $)$ and the corpus callosum $(-$ endoN $=12.05 \pm 3.6$ cells vs + endoN $=$ $183 \pm 59.9$ cells; $p<0.05$, Student's $t$ test $)$.

\section{Neuronal differentiation of neuroblasts in the cortex and striatum}

Immunofluorescence studies with a variety of cell type markers were used to examine the fate of the BrdU-labeled cells that had appeared in the cortex and the striatum at 10 and $21 \mathrm{~d}$. Labeled cells were analyzed by $z$-scanning confocal microscopy, and the percentages of double-labeled cells quantified. Immunostaining for BrdU and the neuronal marker NeuN revealed the presence of double-labeled cells in the cortex (Fig. 7a,b) and striatum (Fig. $7 f, g)$ of endoN-treated animals. A slight increase in the percentage of BrdU/NeuN ${ }^{+}$cells was observed at longer time points, consistent with progressive differentiation (Table 1). In control animals, BrdU/NeuN ${ }^{+}$cells were rarely found in the striatum and were absent in the cortex.

Because the majority of neuroblasts that normally reach the OB differentiate into GABAergic neurons (Lledo et al., 2008), we 

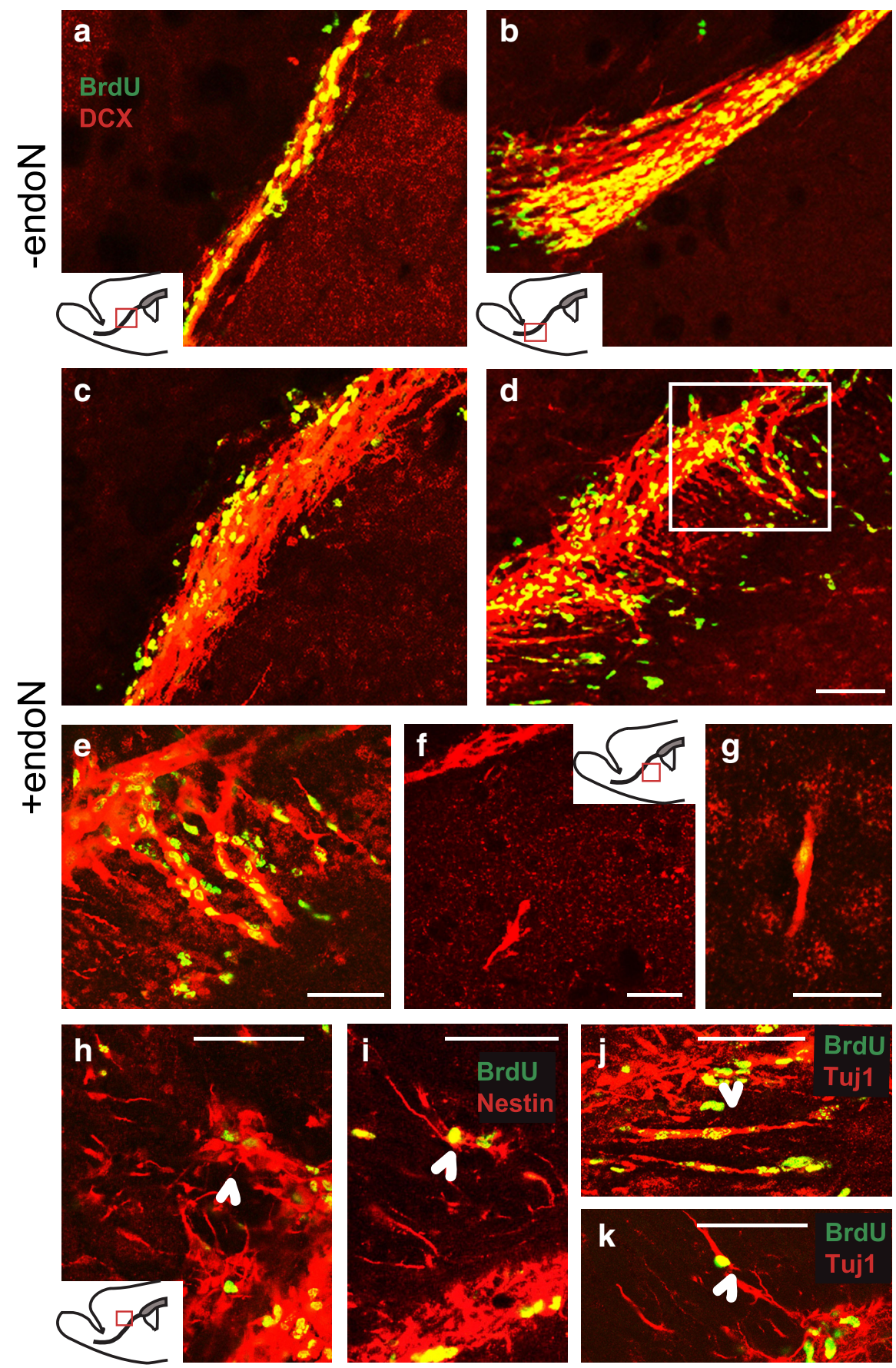

Figure 6. Neuroblast organization $3 \mathrm{~d}$ after PSA removal. $\boldsymbol{a}-\boldsymbol{h}$, Double immunofluorescence labeling of BrdU (green) and DCX (red) of sagittal sections showing the RMS $(\boldsymbol{a}-\boldsymbol{e})$, the striatum $(\boldsymbol{f}, \boldsymbol{g})$, and the corpus callosum $(\boldsymbol{h}) . \boldsymbol{e}$, Higher magnification of the panel outlined in $\boldsymbol{d}$. $\boldsymbol{i}-\boldsymbol{k}$, Double immunofluorescence labeling of BrdU (green) and Nestin (i, red) or TuJ-1 $(\boldsymbol{j}, \boldsymbol{k}$, red) of sagittal sections of the RMS and the corpus callosum. An alteration in the orientation of neuroblast chains was observed after PSA was removed (e). Many neuroblasts seemed to be aligned orthogonally to the normal direction of migration and extended into the surrounding tissue either into the striatal matrix $(\boldsymbol{f}, \boldsymbol{g})$ or the corpus callosum ( $\boldsymbol{h}-\boldsymbol{k}$, arrowheads). cc, Corpus callosum; ctx, cortex; st, striatum. Scale bars: $\boldsymbol{a}-\boldsymbol{d}, \boldsymbol{f}-\boldsymbol{k}, 50 \mu \mathrm{m} ; \boldsymbol{e}, 20 \mu \mathrm{m}$.

analyzed the ectopic neurons for GABAergic markers. Some of the BrdU/NeuN ${ }^{+}$cells in the cortex were positive for GABA (Fig. $7 e$, Table 1), and, interestingly, most of the cells were positive for the calcium-binding protein calretinin (Fig. $7 c, d$, Table 1). The fact that there were more calretinin ${ }^{+}$cells than $\mathrm{GABA}^{+}$cells may be due to differences in immunofluorescence sensitivities or to differences in cell population. None of the $\mathrm{BrdU}^{+}$cells were positive for tyrosine hydroxylase $(\mathrm{TH})$ or the calcium-binding

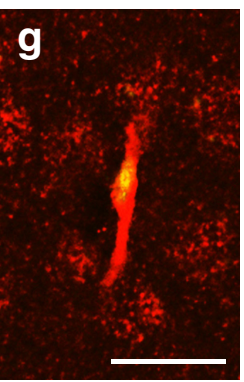

protein calbindin (Table 1). The absence of $\mathrm{TH}$ expression could reflect a lack of input from the environment (Baker, 1990), whereas the absence of calbindin expression may reflect the relatively short experimental time course of our study (Dayer et al., 2005).

The BrdU/NeuN ${ }^{+}$cells in the striatum did not express any of the GABAergic markers. Interestingly, many $\mathrm{BrdU}^{+} /$ $\mathrm{Tuj}^{-1}{ }^{+}$or BrdU ${ }^{+} / \mathrm{DCX}^{+}$cells were seen in the cortex and striatum after $21 \mathrm{~d}$ (Fig. $7 h$, Table 1), indicating that they had remained in an early differentiation state. The phenotype of the remaining BrdU ${ }^{+}$ cell population remained unclear. Only a small percentage of cells were positive for the astrocytic marker GFAP (Table 1) or for the oligodendroglial marker CNPase (data not shown). It should be taken into account, however, that only very clearly double-labeled cells in orthogonal projections through three-dimensionally reconstructed $\mathrm{BrdU}^{+}$cells were considered. Thus, the values obtained could underestimate the frequency of differentiated cells.

\section{NCAM-deficient mice have an altered RMS but no evidence of cell migration out of RMS}

It has been shown that NCAM-deficient mice also have a thicker RMS due to the reduced ability of neuroblasts to migrate tangentially toward the OB (Ono et al., 1994; Chazal et al., 2000), and these animals exhibit some disorganization in their RMS and glial cell morphology (Chazal et al., 2000). As expected, DCX and GFAP immunostaining of $\mathrm{NCAM}^{-/-}$brain revealed a very wide RMS with disorganization of the chain-like structure of neuroblasts, a less compact and less aligned arrangement of astrocytes, and a massive number of $\mathrm{BrdU}^{+}$cells along the RMS (Fig. $8 a-g$ ). However, in contrast to the results of PSA removal from NCAM by endoN, the NCAM-deficient animals did not exhibit an increase in the number of $\mathrm{BrdU}^{+}$nuclei in the striatum, cortex, or corpus callosum after $10 \mathrm{~d}$ (Fig. 8h-j). This surprising finding both emphasizes the uniqueness of the process underlying the neuroblast dispersion observed in the PSA-deficient environment, and points to

NCAM as a critical player in that process.

\section{Discussion}

The initial goal of this study was to analyze the differentiation state of neuroblasts retained in the adult RMS of PSA-depleted mice and to compare them with their normal fate in the OB. Earlier observations suggested that enzymatic removal of PSA in the adult had similar effects on neuroblast migration to those 

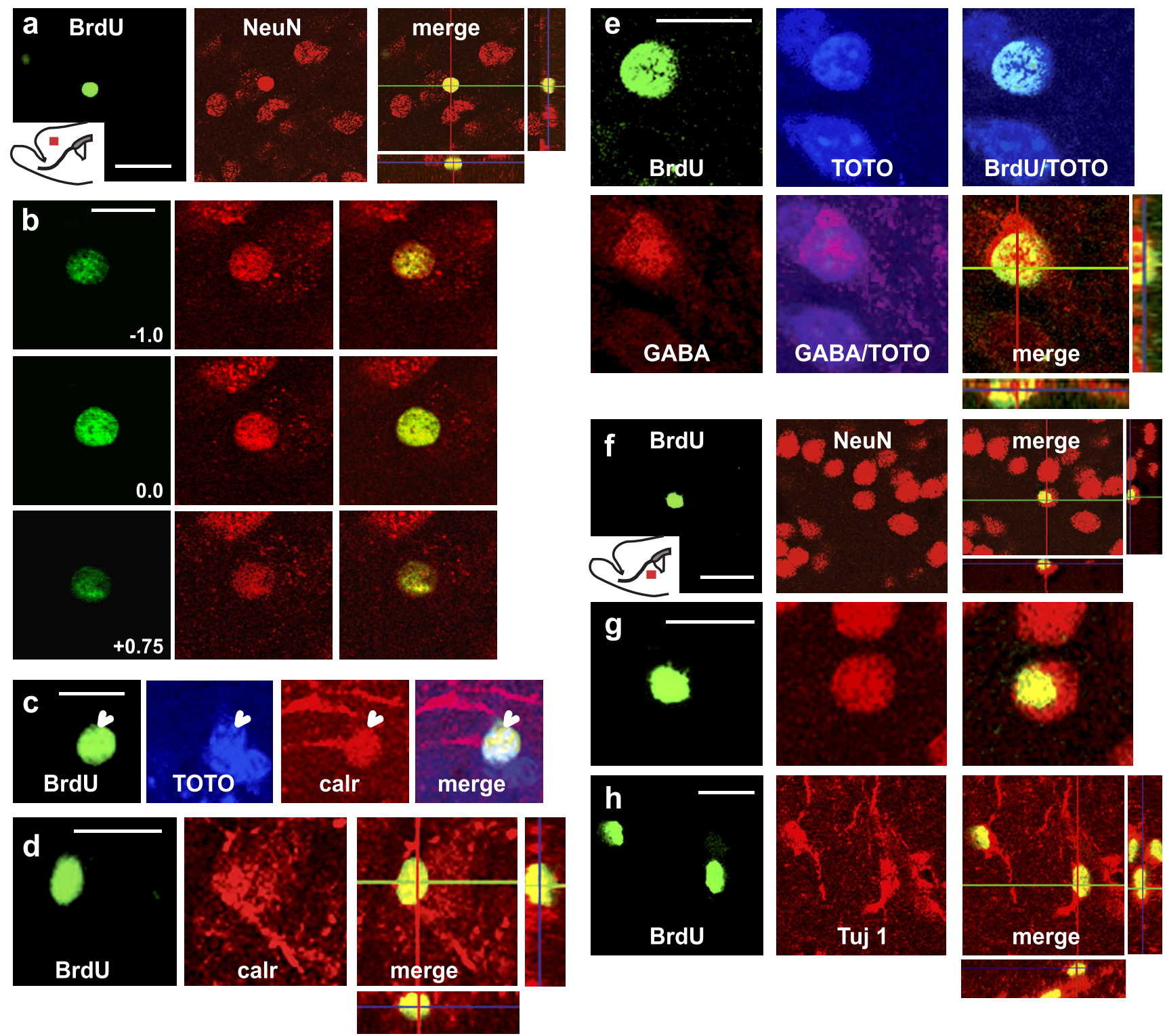

Figure 7. Differentiation of BrdU ${ }^{+}$cells present in the cortex and striatum at $21 \mathrm{~d}$. $\boldsymbol{a}-\boldsymbol{h}$, Confocalz-scanning images of BrdU-double labeled cells with different cell markers. EndoN-injected animals received six consecutive injections of BrdU (twice daily over $3 \mathrm{~d}$ ) and were killed $21 \mathrm{~d}$ after the end of treatment. $\boldsymbol{a}, \boldsymbol{b}$, Confocal micrograph of a BrdU/NeuN ${ }^{+}$cell in the cortex. $\boldsymbol{a}$, An individual $z$-plane is shown with the orthogonal projection (right). $\boldsymbol{b}, z$-axis projections of the same cell shown in $\boldsymbol{a}$. $\boldsymbol{c}-\boldsymbol{e}$, Confocal micrograph of BrdU ${ }^{+}$cells labeled with calretinin ( $\left.\boldsymbol{c}, \boldsymbol{d}\right)$ and GABA (e) in the cortex. Cell nuclei were visualized with TOTO-3 iodide to discriminate positive cells $(\boldsymbol{c}, \boldsymbol{e}) . \boldsymbol{d}, \boldsymbol{e}$, Orthogonal projections of the BrdU-double labeled cells. $\boldsymbol{f}$, Confocal micrograph of a BrdU/NeuN ${ }^{+}$cell in the striatum. $\boldsymbol{g}$, Higher magnification of the double-labeled cells inf. $\boldsymbol{h}$, Confocal micrograph of a BrdU/Tuj ${ }^{+}$cell in the striatum. Some BrdU ${ }^{+}$cells showed labeling with mature neuronal markers such as NeuN. In the cortex, some cells differentiated into specific GABAergic neurons positive for calretinin or GABA, whereas in the striatum a high percentage of cells expressed immature neuronal markers (Table 1). calr, Calretinin. Scale bars: $\boldsymbol{a}, \boldsymbol{f}, 10 \mu \mathrm{m} ; \boldsymbol{b} \boldsymbol{b}, \boldsymbol{g}, \boldsymbol{h}, 20 \mu \mathrm{m}$.

Table 1. Expression of differentiation markers by BrdU ${ }^{+}$cells

\begin{tabular}{llllll}
\hline & Cortex & & & Striatum \\
\cline { 2 - 3 } \cline { 5 - 6 } & $10 \mathrm{~d}$ & $21 \mathrm{~d}$ & & $10 \mathrm{~d}$ & $21 \mathrm{~d}$ \\
\hline DCX/Tuj1 & & $18.9 \pm 6.7$ & & $33.3 \pm 11.6$ \\
NeuN & $6.6 \pm 2.2$ & $13.0 \pm 2.1$ & & $10.3 \pm 3.7$ & $17.8 \pm 9.6$ \\
Calretinin & $7.8 \pm 3.2$ & $15.0 \pm 4.5$ & & 0 & 0 \\
Calbindin & 0 & 0 & 0 & 0 \\
GABA & 0 & $2.2 \pm 0.45$ & 0 & 0 \\
TH & $13.4 \pm 6.0$ & $4.1 \pm 0.7$ & & 0 & \\
GFAP & 0 & &
\end{tabular}

Values are expressed as the mean \pm SEM.

observed in NCAM mutant mouse (Ono et al., 1994; Hu et al., 1996). However, the present study using BrdU labeling shows that these two PSA-negative animals differ in several aspects. Most conspicuously, the small OB in the NCAM mutants results from a reduced ability of cells to migrate tangentially within the RMS, whereas in the endoN-treated animals it results additionally from dispersal of the cells from the RMS into surrounding brain regions (Fig. 9). In contrast, the differentiation state of the cells is reminiscent of that which they exhibit in the $\mathrm{OB}$. The following discussion focuses on the possible mechanisms underlying these observations: at the cellular level for RMS astrocytic tubes and migrating neuroblasts, and at the molecular level for PSA and NCAM.

In the RMS, enzymatic removal of PSA in the adult causes a major disorganization and disruption of normal neuroblast and astrocyte alignment. On the other hand, the genetic deletion of the NCAM gene results in a widening but otherwise relatively mild disorganization of the RMS with cell processes remaining aligned in the direction of tangential migration (Chazal et al., 2000; Decker et al., 2002). These findings support our suggestion 



10 days
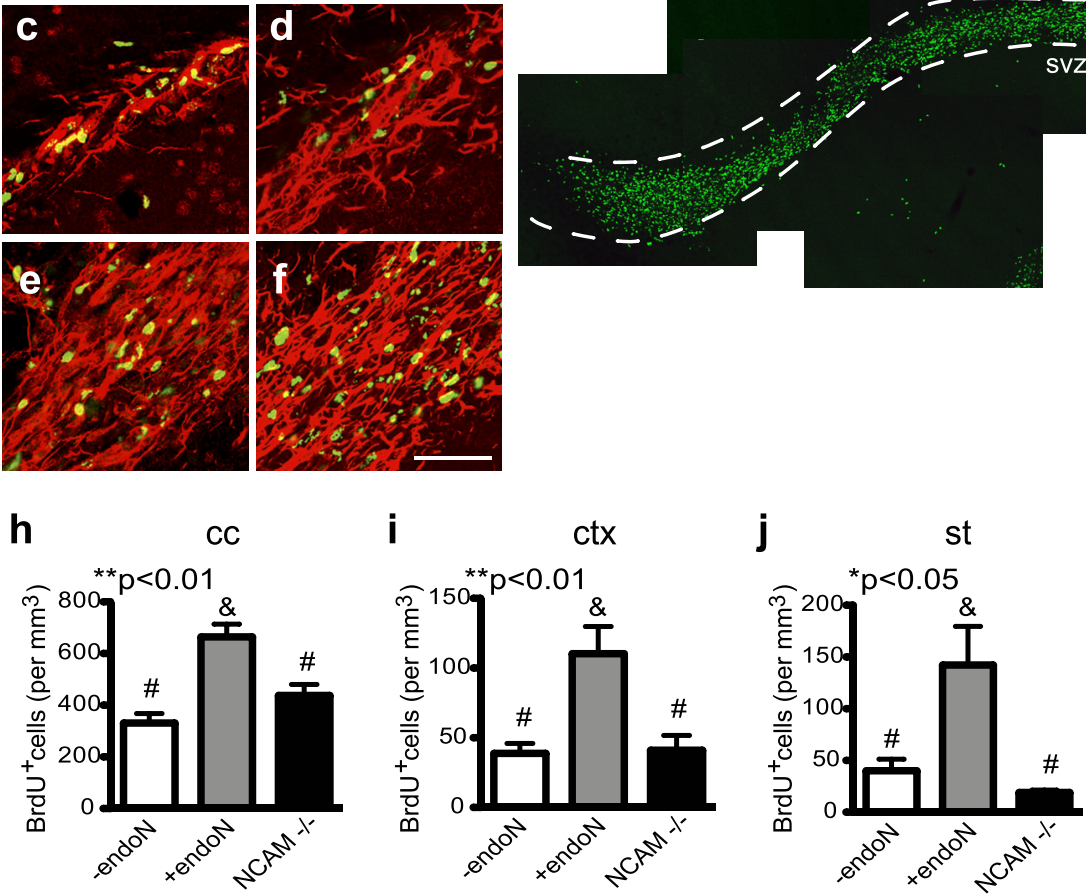

Figure 8. Organization of the RMS and BrdU ${ }^{+}$cells in NCAM-deficient mutant mice. $\boldsymbol{a}-\boldsymbol{f}$, Immunofluorescence for BrdU (green) and DCX ( $\boldsymbol{a}, \boldsymbol{c}, \boldsymbol{e}$, red) or GFAP $(\boldsymbol{b}, \boldsymbol{d}, \boldsymbol{f}$, red) of sagittal sections of the RMS of control $(\boldsymbol{a}, \boldsymbol{b})$, endoN-treated $(\boldsymbol{c}, \boldsymbol{d})$, and NCAM-deficient $(\boldsymbol{e}, \boldsymbol{f})$ mice at $10 \mathrm{~d} . \boldsymbol{g}$, BrdU staining of sagittal sections of the RMS (dotted line) of NCAM-deficient mice. $\boldsymbol{h}-\boldsymbol{j}$, Comparison of the number of BrdU ${ }^{+}$cells in the corpus callosum (h), cortex (i), and striatum $(\boldsymbol{j})$ among control, endoN-injected, and NCAM-deficient mice $10 \mathrm{~d}$ after the BrdU injection. NCAM-deficient mice had a wide and disorganized RMS with many BrdU ${ }^{+}$nuclei; however, the number of positive cells outside the RMS was similar to that for control mice. Values are the mean $\pm \mathrm{SEM} ;{ }^{*} p<0.05,{ }^{* *} p<0.01$, ANOVA, with Bonferroni post-test ( - endoN, $n=5$; + endoN $n=$ $\left.5 ; \mathrm{NCAM}^{-1-}, n=4\right)$. cc, Corpus callosum; ctx, cortex; st, striatum. Scale bars: $\boldsymbol{a}-\boldsymbol{f}, 50 \mu \mathrm{m} ; \boldsymbol{g}, 100 \mu \mathrm{m}$.
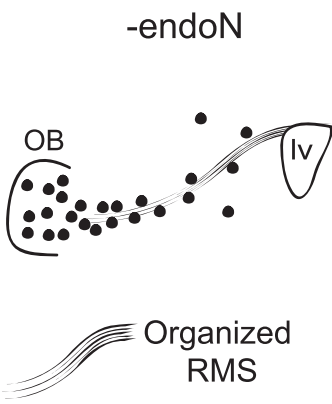
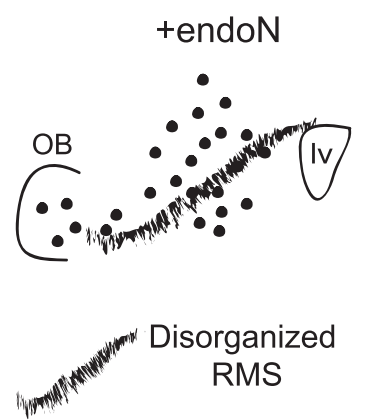

NCAM -/-


ide and partially disorganized
Figure 9. Comparison of RMS structure and BrdU staining in endoN-treated and NCAM-deficient mice. Schematic diagram showing the structure of the RMS and the appearance of BrdU ${ }^{+}$cells (dots) at $10 \mathrm{~d}$ among control (-endoN), PSA-depleted (+endoN), and NCAM-deficient (NCAM ${ }^{-1-}$ ) mice. In the absence of PSA-NCAM, cells failed to migrate to the $O B$ and accumulated along the RMS, whereas when PSA was removed cells dispersed from the RMS into the surrounding tissue, where they maintained their ability to differentiate into neurons. The large difference in BrdU ${ }^{+}$cell distribution is accompanied by more subtle differences in the organization of the RMS. NCAM-deficient mice show a partially disorganized astrocytic tube-like organization, maintaining part of the structure seen in control RMS, where neuroblasts are arranged in chains aligned parallel to the direction of migration. When PSA is depleted the overall organization of the RMS is disrupted. Iv, Lateral ventricle. that the migration characteristics of the RMS are profoundly altered by removal of PSA alone. The fact that in endoN-treated brains the dispersed distribution of BrdUlabeled cells increases with time, in terms of both numbers and distance from the RMS, is also consistent with progressive movement of these cells out of and away from their normal pathway. In addition, the alternative that these cells arise by a diffuse pattern of NCAM-induced cell proliferation is not likely given that the total numbers of BrdU-labeled cells did not increase detectably in our experiments, and the fact that enhancement of cell division has not been observed in other studies using either endoN-treated or NCAM-deficient mice (Ono et al., 1994; Chazal et al., 2000; Decker et al., 2002).

The finding that endoN treatment can enhance cell dispersion from the RMS is in sharp contrast to the many systems in which PSA removal has been found to decrease cell or axon migration (Rutishauser, 2008), suggesting that the present phenomena are more complex than a direct effect on migration-promoting interactions among the RMS cells. Two possibilities that are consistent with our findings are (1) an alteration of astrocyte behavior/ morphology that could disrupt containment of neuroblasts or support neuroblast dispersion and (2) an NCAM-dependent triggering of neuroblast differentiation that includes new PSA-independent migratory properties.

The observed major changes in astrocyte morphology (in addition to being misaligned, PSA-negative RMS astrocytes generally had shorter, thicker processes) might suggest that confinement of the neuroblasts by a glial tube has been compromised. However, it seems unlikely that neuroblast dispersal in the endoN-treated animal is simply a case of porosity, in that the NCAM mutant, which also has a dramatically loosened RMS architecture, does not display this type of migration pattern. On the other hand, the alignment of the astrocytes and dispersing neuroblasts in the endoN-treated brain could be indicative of a supportive relationship in the dispersion process.

There is clear evidence that NCAMmediated cell interactions in the absence of PSA can result in cell differentiation (Amoureux et al., 2000; Decker et al., 2000; Seidenfaden et al., 2003; Petridis et al., 2004; Angata et al., 2007; Röckle et al., 2008). Does the observed effect of endoN on neuroblast dispersal reflect a differentiation-linked event? In support of this hypothesis, it may be noted that radial migration of cells 
in the OB (Whitman and Greer, 2009) and developing cerebellum (Hatten, 2002) occurs precisely when PSA expression is downregulated. In this respect, it is interesting to speculate that the expression of PSA in vertebrates (but not invertebrates) represents not only an enhancement of long-range postmitotic migration, but also a delay in differentiation until these cells have reached their proper positions (Rutishauser, 2008). Thus, removal of PSA from the RMS may in part be revealing a cryptic, perhaps vestigial, cell contact-dependent differentiation signal for neuroblasts.

The ability of either PSA removal or NCAM deletion to increase migration of neuroblasts toward a demyelinating lesion in the corpus callosum has been reported previously (Decker et al., 2002), indicating that under certain circumstances the lack of PSA may be permissive for migration. Interestingly, the enhanced migration in this study occurred both in the presence and absence of NCAM, in contrast to our results with the NCAM-deficient mice. This difference may to be due to differences in the environment caused by the lesion.

Some of the $\mathrm{BrdU}^{+}$cells present in the cortex of PSA-depleted mice are able to acquire a neuronal phenotype, including calreti$\operatorname{nin}^{+}$GABAergic interneurons reminiscent of their normal fate in the OB. However, newly generated cells in the normal adult rat cortex also differentiate into GABAergic interneurons that express calretinin and calbindin (Dayer et al., 2005). A positive effect of NCAM on calretinin ${ }^{+}$differentiation of SVZ neural precursors has been found both in culture (Röckle et al., 2008) and in STSiaII/STSiaIV knock-out mice (Angata et al., 2007). In any case, many of the BrdU-labeled neuroblasts did not express mature neuronal markers, and it is not clear whether they are unable to differentiate or require more time to establish these fates.

Finally, several studies suggest that small numbers of adult rat SVZ-RMS neuroblasts are able to migrate into the striatal matrix (Dayer et al., 2005); in some cases in response to injury and with possible therapeutic value (Magavi and Macklis, 2001; Arvidsson et al., 2002; El Maarouf et al., 2006; Zhang et al., 2007; Faiz et al., 2008). In this respect, one can view the present results with enzymatic removal of PSA as a potential tool for enhancing the recruitment of progenitors to a lesion and thus the potential for repair.

\section{References}

Alonso G, Prieto M, Chauvet N (1999) Tangential migration of young neurons arising from the subventricular zone of adult rats is impaired by surgical lesions passing through their natural migratory pathway. J Comp Neurol 405:508-528.

Altman J (1969) Autoradiographic and histological studies of postnatal neurogenesis. IV. Cell proliferation and migration in the anterior forebrain, with special reference to persisting neurogenesis in the olfactory bulb. J Comp Neurol 137:433-457.

Amoureux MC, Cunningham BA, Edelman GM, Crossin KL (2000) $\mathrm{N}$-CAM binding inhibits the proliferation of hippocampal progenitor cells and promotes their differentiation to a neuronal phenotype. J Neurosci 20:3631-3640.

Angata K, Huckaby V, Ranscht B, Terskikh A, Marth JD, Fukuda M (2007) Polysialic acid-directed migration and differentiation of neural precursors are essential for mouse brain development. Mol Cell Biol 27:6659-6668

Arvidsson A, Collin T, Kirik D, Kokaia Z, Lindvall O (2002) Neuronal replacement from endogenous precursors in the adult brain after stroke. Nat Med 8:963-970.

Baker H (1990) Unilateral, neonatal olfactory deprivation alters tyrosine hydroxylase expression but not aromatic amino acid decarboxylase or GABA immunoreactivity. Neuroscience 36:761-771.

Bonfanti L, Theodosis DT (1994) Expression of polysialylated neural cell adhesion molecule by proliferating cells in the subependymal layer of the adult rat, in its rostral extension and in the olfactory bulb. Neuroscience 62:291-305.

Carleton A, Petreanu LT, Lansford R, Alvarez-Buylla A, Lledo PM (2003) Becoming a new neuron in the adult olfactory bulb. Nat Neurosci 6:507-518.

Chazal G, Durbec P, Jankovski A, Rougon G, Cremer H (2000) Consequences of neural cell adhesion molecule deficiency on cell migration in the rostral migratory stream of the mouse. J Neurosci 20:1446-1457.

Cremer H, Lange R, Christoph A, Plomann M, Vopper G, Roes J, Brown R, Baldwin S, Kraemer P, Scheff S (1994) Inactivation of the N-CAM gene in mice results in size reduction of the olfactory bulb and deficits in spatial learning. Nature 367:455-459.

Dayer AG, Cleaver KM, Abouantoun T, Cameron HA (2005) New GABAergic interneurons in the adult neocortex and striatum are generated from different precursors. J Cell Biol 168:415-427.

Decker L, Avellana-Adalid V, Nait-Oumesmar B, Durbec P, Baron-Van Evercooren A (2000) Oligodendrocyte precursor migration and differentiation: combined effects of PSA residues, growth factors, and substrates. Mol Cell Neurosci 16:422-439.

Decker L, Durbec P, Rougon G, Evercooren AB (2002) Loss of polysialic residues accelerates CNS neural precursor differentiation in pathological conditions. Mol Cell Neurosci 19:225-238.

De Marchis S, Fasolo A, Puche AC (2004) Subventricular zone-derived neuronal progenitors migrate into the subcortical forebrain of postnatal mice. J Comp Neurol 476:290-300.

Eckhardt M, Bukalo O, Chazal G, Wang L, Goridis C, Schachner M, GerardySchahn R, Cremer H, Dityatev A (2000) Mice deficient in the polysialyltransferase ST8SiaIV/PST-1 allow discrimination of the roles of neural cell adhesion molecule protein and polysialic acid in neural development and synaptic plasticity. J Neurosci 20:5234-5244.

El Maarouf A, Rutishauser U (2003) Removal of polysialic acid induces aberrant pathways, synaptic vesicle distribution, and terminal arborization of retinotectal axons. J Comp Neurol 460:203-211.

El Maarouf A, Petridis AK, Rutishauser U (2006) Use of polysialic acid in repair of the central nervous system. Proc Natl Acad Sci U S A 103:16989-16994.

Faiz M, Acarin L, Villapol S, Schulz S, Castellano B, Gonzalez B (2008) Substantial migration of SVZ cells to the cortex results in the generation of new neurons in the excitotoxically damaged immature rat brain. Mol Cell Neurosci 38:170-182.

Goings GE, Sahni V, Szele FG (2004) Migration patterns of subventricular zone cells in adult mice change after cerebral cortex injury. Brain Res 996:213-226.

Hallenbeck PC, Vimr ER, Yu F, Bassler B, Troy FA (1987) Purification and properties of a bacteriophage-induced endo- $\mathrm{N}$-acetylneuraminidase specific for poly-alpha-2,8-sialosyl carbohydrate units. J Biol Chem 262:3553-3561.

Hatten ME (2002) New directions in neuronal migration. Science 297:16601663

Hu H, Tomasiewicz H, Magnuson T, Rutishauser U (1996) The role of polysialic acid in migration of olfactory bulb interneuron precursors in the subventricular zone. Neuron 16:735-743.

Inta D, Alfonso J, von Engelhardt J, Kreuzberg MM, Meyer AH, van Hooft JA, Monyer H (2008) Neurogenesis and widespread forebrain migration of distinct GABAergic neurons from the postnatal subventricular zone. Proc Natl Acad Sci U S A 105:20994-20999.

Iwai M, Sato K, Kamada H, Omori N, Nagano I, Shoji M, Abe K (2003) Temporal profile of stem cell division, migration, and differentiation from subventricular zone to olfactory bulb after transient forebrain ischemia in gerbils. J Cereb Blood Flow Metab 23:331-341.

Kosaka K, Aika Y, Toida K, Heizmann CW, Hunziker W, Jacobowitz DM, Nagatsu I, Streit P, Visser TJ, Kosaka T (1995) Chemically defined neuron groups and their subpopulations in the glomerular layer of the rat main olfactory bulb. Neurosci Res 23:73-88.

Lledo PM, Merkle FT, Alvarez-Buylla A (2008) Origin and function of olfactory bulb interneuron diversity. Trends Neurosci 31:392-400.

Lois C, Alvarez-Buylla A (1994) Long-distance neuronal migration in the adult mammalian brain. Science 264:1145-1148.

Luskin MB, Parnavelas JG, Barfield JA (1993) Neurons, astrocytes, and oligodendrocytes of the rat cerebral cortex originate from separate progenitor cells: an ultrastructural analysis of clonally related cells. J Neurosci 13:1730-1750. 
Luzzati F, Peretto P, Aimar P, Ponti G, Fasolo A, Bonfanti L (2003) Gliaindependent chains of neuroblasts through the subcortical parenchyma of the adult rabbit brain. Proc Natl Acad Sci U S A 100:13036-13041.

Magavi SS, Macklis JD (2001) Manipulation of neural precursors in situ: induction of neurogenesis in the neocortex of adult mice. Neuropsychopharmacology 25:816-835.

Ono K, Tomasiewicz H, Magnuson T, Rutishauser U (1994) N-CAM mutation inhibits tangential neuronal migration and is phenocopied by enzymatic removal of polysialic acid. Neuron 13:595-609.

Peretto P, Merighi A, Fasolo A, Bonfanti L (1997) Glial tubes in the rostral migratory stream of the adult rat. Brain Res Bull 42:9-21.

Peretto P, Merighi A, Fasolo A, Bonfanti L (1999) The subependymal layer in rodents: a site of structural plasticity and cell migration in the adult mammalian brain. Brain Res Bull 49:221-243.

Petridis AK, El-Maarouf A, Rutishauser U (2004) Polysialic acid regulates cell contact-dependent neuronal differentiation of progenitor cells from the subventricular zone. Dev Dyn 230:675-684.

Röckle I, Seidenfaden R, Weinhold B, Mühlenhoff M, Gerardy-Schahn R, Hildebrandt H (2008) Polysialic acid controls NCAM-induced differentiation of neuronal precursors into calretinin-positive olfactory bulb interneurons. Dev Neurobiol 68:1170-1184.

Rousselot P, Lois C, Alvarez-Buylla A (1995) Embryonic (PSA) N-CAM reveals chains of migrating neuroblasts between the lateral ventricle and the olfactory bulb of adult mice. J Comp Neurol 351:51-61.

Rutishauser U (1998) Polysialic acid at the cell surface: biophysics in service of cell interactions and tissue plasticity. J Cell Biochem 70:304-312.

Rutishauser U (2008) Polysialic acid in the plasticity of the developing and adult vertebrate nervous system. Nat Rev Neurosci 9:26-35.
Seidenfaden R, Krauter A, Schertzinger F, Gerardy-Schahn R, Hildebrandt H (2003) Polysialic acid directs tumor cell growth by controlling heterophilic neural cell adhesion molecule interactions. Mol Cell Biol 23:59085918.

Suzuki SO, Goldman JE (2003) Multiple cell populations in the early postnatal subventricular zone take distinct migratory pathways: a dynamic study of glial and neuronal progenitor migration. J Neurosci 23:4240-4250.

Tomasiewicz H, Ono K, Yee D, Thompson C, Goridis C, Rutishauser U, Magnuson T (1993) Genetic deletion of a neural cell adhesion molecule variant (N-CAM-180) produces distinct defects in the central nervous system. Neuron 11:1163-1174.

Vimr ER, McCoy RD, Vollger HF, Wilkison NC, Troy FA (1984) Use of prokaryotic-derived probes to identify poly(sialic acid) in neonatal neuronal membranes. Proc Natl Acad Sci U S A 81:1971-1975.

Weinhold B, Seidenfaden R, Röckle I, Mühlenhoff M, Schertzinger F, Conzelmann S, Marth JD, Gerardy-Schahn R, Hildebrandt H (2005) Genetic ablation of polysialic acid causes severe neurodevelopmental defects rescued by deletion of the neural cell adhesion molecule. J Biol Chem 280:42971-42977.

Whitman MC, Greer CA (2009) Adult neurogenesis and the olfactory system. Prog Neurobiol 89:162-175

Zhang RL, LeTourneau Y, Gregg SR, Wang Y, Toh Y, Robin AM, Zhang ZG, Chopp M (2007) Neuroblast division during migration toward the ischemic striatum: a study of dynamic migratory and proliferative characteristics of neuroblasts from the subventricular zone. J Neurosci 27:3157-3162. 